\title{
Navorsings-en oorsigartikels
}

\section{Elektronpresipitasie in die bo-atmosfeer te Sanae}

\author{
P.H. Stoker \\ Departement Fisika, Potchefstroomse Universiteit vir Christelike Hoër Onderwys, Potchefstroom, 2520 \\ Ontvang 13 Maart 1995; aanvaar 3 Julie 1995
}

UITTREKSEL

Liguitstraling vanaf auroras word veroorsaak deur botsingsprosesse van elektrone met atmosferiese bestanddele in die E- en F-lae van die ionosfeer, hoofsaaklik bo $100 \mathrm{~km}$ hoogte. Dit volg uit studies van spektraallyne van auroras. Die absorpsie van omtrent tien meter golflengte kosmiese radioruis vind oorwegend onder $90 \mathrm{~km}$ hoogte plaas. Hierdie waarnemings wat met riometers gedoen word, is die gevolg van 'n toename in elektrondigthede in die ionosferiese D. laag. Omdat uitstraling en absorpsie deur presipiterende elektrone in verskillende energiegebiede veroorsaak word, kan uit gelyktydige waarnemings van aurorautstraling en aurora-absorpsie inligting omtrent die spektrum en veranderinge in die spektrum van invallende elektrone afgelei word. In hierdie artikel word korrelasiestudies in tyd en in ruimtelike uitgebreidheid van auroragebeurtenisse bespreek. Die studie is te Sanae, Antarktika, moontlik gemaak deur die gebruik van hoëtegnologie met vinnige monstering van syferdata vanaf beeldriometers met smal kykrigtings en TV-stelsels met lae ligulakke.

\section{Amstract}

\section{Electron precipitation into the upper atmosphere at Sanae}

Auroral light emissions are due to collisional processes of electrons with atmospheric constituents and occur primarily above $100 \mathrm{~km}$ in the ionospheric $E$ - and F-layers, according to studies on excitation of emission lines. The absorption of about ten metre wavelength cosmic radio noise energy, as observed by riometers, occurs mainly below $90 \mathrm{~km}$ due to an increase of electron concentration in the ionospheric D-layer. Because auroral luminosity and auroral absorption are produced mainly by electrons in different energy regions, simultaneous observations will provide information on the energy spectrum of the incident electrons and on spectral changes of these precipitating electrons during auroral events. With current modern techniques of fast sampling rates of digital recordings with narrow beam imaging riometers and low light level TV systems available at Sanae, Antarctica, we report in this paper on correlation studies in time and in spatial dimensions of auroral events.

\section{INLEIDING}

Poolligte, of aurora, ontstaan wanneer elektrone uit die magnetosfeer in die boonste atmosfeer presipiteer. Hierdie elektrone ioniseer die F-laag van die ionosfeer van bo tot op 'n hoogte van ongeveer $105 \mathrm{~km}$, soos volg uit studies van opwekking van spektraallyne van suurstof en stikstof.' Meer energieke elektrone (energie groter as $40 \mathrm{keV}$ ) presipiteer ook soms in die atmosfeer en ioniseer die Dlaag van bo tot hoogtes onder $90 \mathrm{~km}$, waar kosmiese radiogolwe met frekwensies $\geq 20 \mathrm{MHz}$ deur die toename van vry elektrone in die atmosfeer geabsorbeer word. ${ }^{1}$ Ionisasie deur hierdie meer energieke elektrone veroorsaak dat onewe waterstof- en onewe stikstofverbindings in die bo-atmosfeer ontstaan. Hierdie verbindings reageer op osoon en verminder die osoonkonsentrasie in die atmosfeer. Onewe stikst of kan vir dae tot maande in die atmosfeer bly, afhangende van die hoogte van sy vorming en die transport na vorming.

Op Sanae, Antarktika, word die deursigtigheid van die ionosfeer deur kosmiese radiogolwe met frekwensies van 20, 30 en 51,4 MHz bepaal, volgens 'n Antarktiese navorsingsprogram van die Eenheid van Ruimtenavorsing van die Potchefstroomse Universiteit vir C.H.O. Die intensiteit van hierdie radiogolwe, wat uit die heelal afkomstig is, word deur riometers (relative ionospheric opacitymeter) met wyehoek $\left( \pm 34^{\circ}\right)$-antennes deurlopend sedert 1964 geregistreer. Wanneer die atmosfeer onder 'n hoogte van ongeveer $90 \mathrm{~km}$ voldoende geïoniseer word, verswak die intensiteit van hierdie golwe.' Hierdie absorpsies (verswakking in die intensiteit van radiogolwe) word dan geregistreer wanneer energieke elektrone in die atmosfeer presipiteer maar ook as X-strale of ultraviolet lig vanaf 'n sonvlam die D-laag ioniseer. Laasgenoemde absorpsies word selde op Sanae gesien omdat lig van die son daar gewoonlik baie skuins deur die atmosfeer inval en hierdie kortgolfstrale reeds geabsorbeer is voordat die diepte van die D-laag bo Sanae bereik word. ${ }^{2}$ Die doel van hierdie artikel is om onlangse en nuwe resultate, wat uit riometerabsorpsies afgelei is, te vergelyk met optiese aurora-intensiteite, wat uit die videowaarnemings van die Instituut van Ruimtefisika van die Universiteit van Natal, Durban, afgelei is, en die fisiese kennis, wat daaruit voortvloei, te bespreek. 


\section{MAGNETOSFEER EN MAGNETIESE STORM ${ }^{\prime}$}

Die magneetveld van die aarde word aan die dagkant saamgedruk en aan die nagkant tot 'n lang stert uitgerek, deurdat magneetveldlyne deur die sonwind meegesleur word (kyk figuur 1). Die holte wat die aarde se magneetveld in die verbybewegende sonwind bepaal, word die magnetosfeer genoem. Die sonwind is hoofsaaklik 'n waterstofplasma van lae digtheid met 'n hoë temperatuur van sowat $500000 \mathrm{~K}$. Uitbarstings op die son, wat as sonvlamme waargeneem word, laat die sonwind met wisselende digthede om die magnetosfeer verbybeweeg. Daardeur ontstaan trillinge in die magnetosfeer wat as magnetiese aktiwiteit op aarde geregistreer word en wat 'n magnetiese storm genoem word. Hierdie trillinge in die aarde se magneetveld veroorsaak elektriese velde, waardeur die plasma van die sonwind in die magnetosfeer in diffundeer en versnel. Elektriese velde ontstaan ook deur wrywing in die beweging van die sonwind om die magnetosfeer. Al hierdie prosesse gee aan die magnetosfeer 'n komplekse struktuur.

'n Plasmasfeer lê binne die gebied van geslote magneetveldlyne. Poolwaarts grens hierdie gebied aan die auroragordel. Die poolgebied, wat deurdie auroragordel omsluit word, is die poolkap met oop magneetveldlyne. Van hierdie oop lyne sluit aan by die interplanetêre magneetveld wanneer hierdie magneetveld vanaf die son 'n suidgerigte komponent by die aarde het. Andersins verloop die veldlyne vanaf die poolkap na die stertgebied van die magnetosfeer. Sanae (figuur I) is normaalweg binne die plasmasfeer geleë, in afwesigheid van geomagnetiese aktiwiteit. Aurora word dan vanaf Sanae op die suidelike horison waargeneem Die plasmapouse skuif oor die veldlyne vanaf Sanae wanneer die magnetiese aktiwiteitsindeks $K_{\text {g }}$ groter as $\sim 4$ gedurende die nag word en gevolglik skuif die aurora dan oor Sanae.

Magnetiese substorms word dikwels gedurende 'n magnetiese storm waargeneem. 'n Magnetiese substorm ontstaan wanneer magneetveldlyne in die naby stertgebied van die magnetosfeer saamsmelt. Deur saamtrekking van hierdie nuutverbinde lyne word deeltjies uit die plasmalaag na die omgewing van die auroragordel versnel. 'n Vinnige poolwaartse beweging van auroravorme vind dan plaas as gevolg van presipitasie van die versnelde elektrone en protone by die voetpunte van hierdie nuutverbinde veldlyne.

\section{FREKWENSIEAFHANKLIKHEID VAN RIOMETERABSORPSIES}

Dit volg uit die Appleton-Hartree-benadering ${ }^{1}$ dat die absorpsie $A\left(f_{e}\right)$ van radiogolwe met frekwensie $f_{e}$ gegee word deur $A\left(f_{e}\right) \propto f_{e}^{-2}$ indien die hoekfrekwensie $2 \pi f_{c}$ kleiner is as die effektiewe botsingsfrekwensie van vry elektrone met die neutrale atmosfeer, soos dit die geval is by hoogtes $>70 \mathrm{~km}$. By laer hoogtes geld hierdie benadering nie meer nie en moet ons skryf $A\left(f_{e}\right) \propto f_{e}^{-n}$, met die spektraalindeks $n<2,0$. Stoker ${ }^{3}$ het deur simulasie-

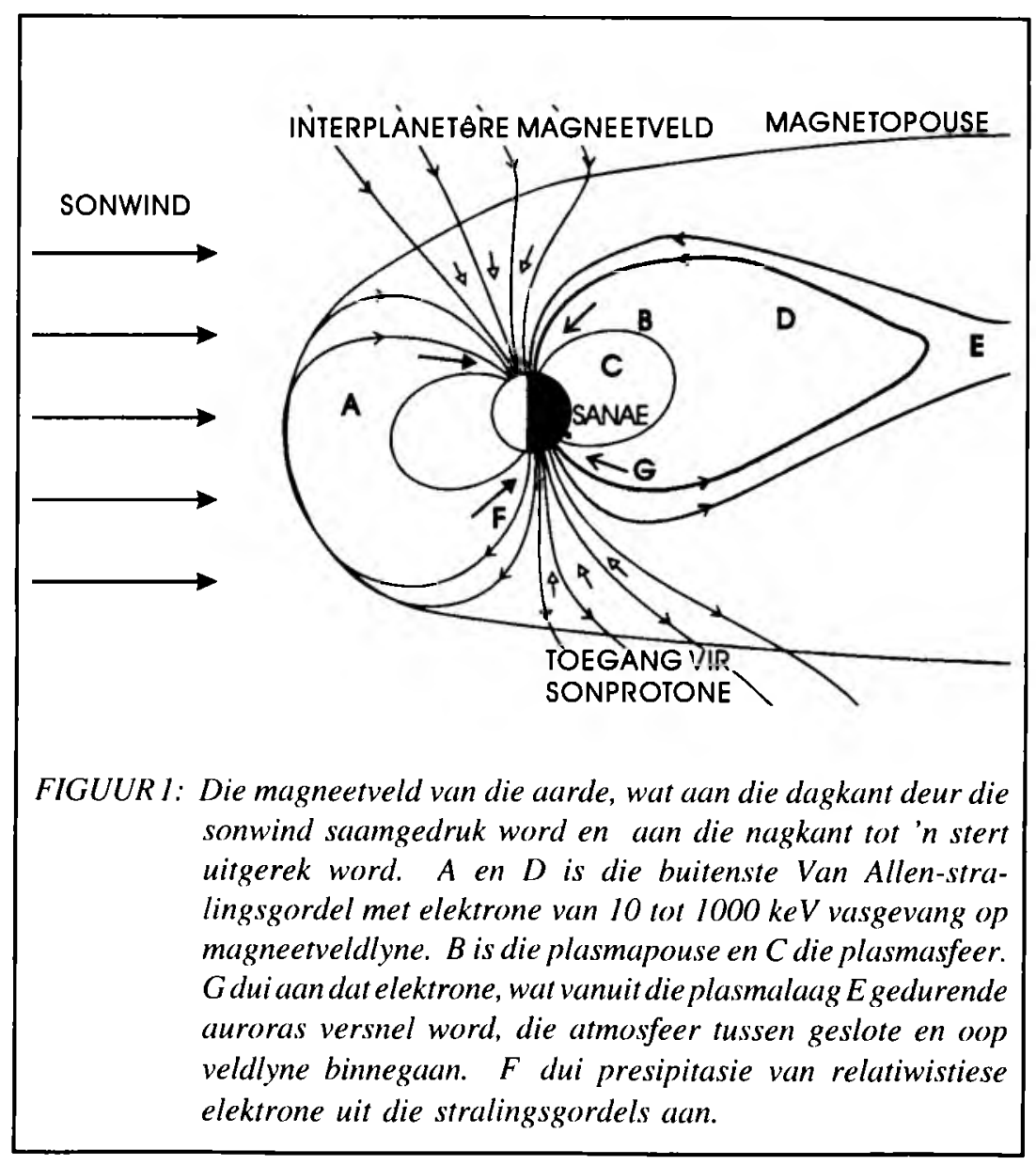




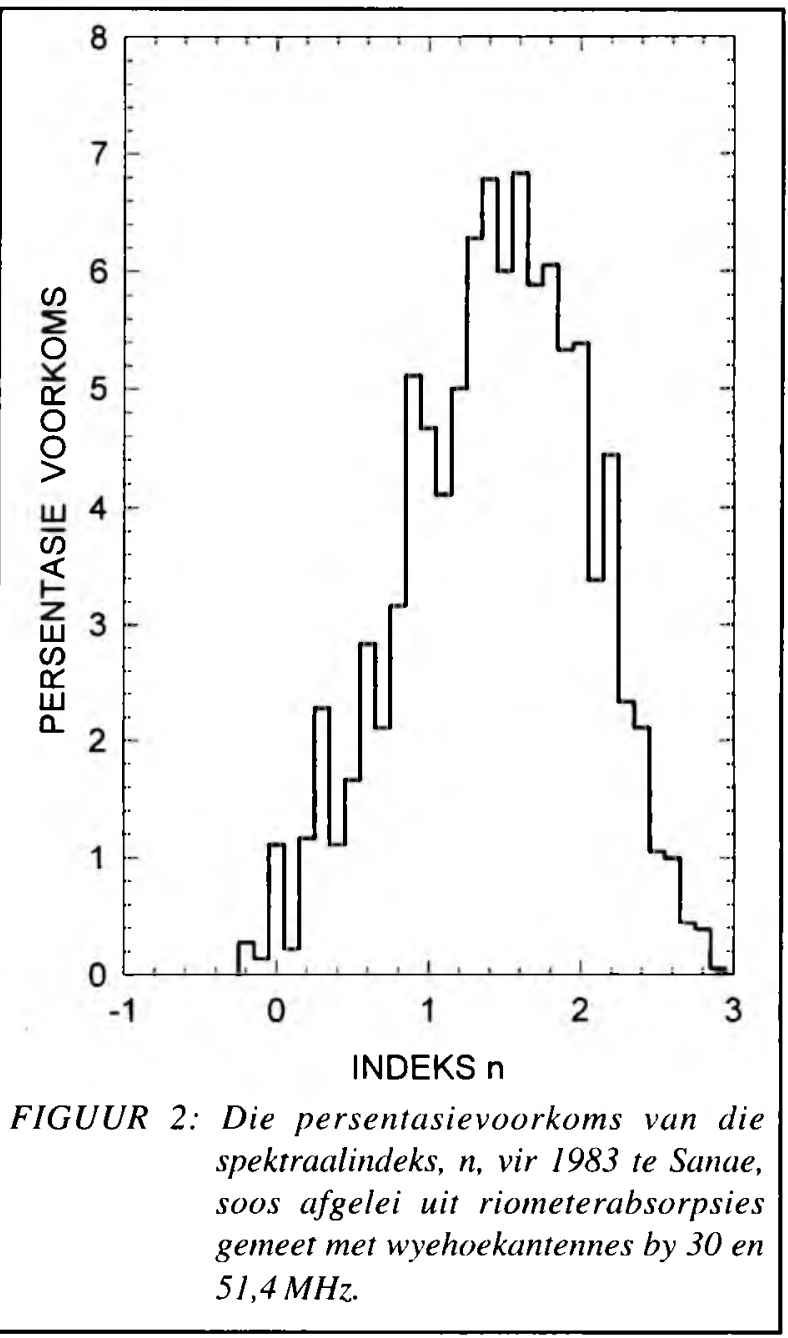

berekeninge vir riometers met wyehoekantennes aangetoon dat die laer hoogtes maar'n geringe invloed op die spektraalindeks het, selfs vir harde elektronspektra wat die atmosfeer van bo tot baie laer as $70 \mathrm{~km}$ ioniseer. Die berekeninge toon dat $n \approx 2,0$ bly, mits die elektrone isotroop uit alle rigtings en ruimtelik uniform op die atmosfeer inval. Indien die inval nie ruimtelik uniform is nie, maar strukture vertoon, soos strukture wat in optiese aurora gesien word, kan die indeks baie kleiner as 2,0 word.

In figuur 2 is ' $n$ histogram geteken ${ }^{4}$ van die spektraalindeks, $\mathrm{n}$, soos bereken uit 4-minuut-gemiddeldes van absorpsies van 30 en $51,4 \mathrm{MHz}$ kosmiese radiogolwe, wat gedurende 1983 te Sanae met wyehoekantennes geregistreer is. Hieruit blyk dit dat die mees waarskynlike waarde van $n \sim 1,5$ is. Hierdie resultaat bevestig in die lig van die simulasieberekeninge dat energieke elektrone, net soos die sagter elektrone wat aurora veroorsaak, in ruimtelike strukture presipiteer.

In Januarie 1991 is 'n 16-rigting-beeldriometerte Sanae opgerig om ruimtelike strukture in die presipitasie van energieke elektrone te bestudeer. Die punte op figuur 3 dui die maksima van die 16 ontvangsrigtings, geprojekteer op 'n vlak $90 \mathrm{~km}$ bo die aardoppervlak, aan, terwyl die lusse kontoere van die helftes $(-3 \mathrm{~dB})$ van maksimum intensiteite is. ${ }^{5}$ Die gebreekte sirkel is die $-3 \mathrm{~dB}$-kontoer van die wyehoekantenne. Kosmiese radioruis van $51,4 \mathrm{MHz}$ is te Sanae vanaf Februarie 1991 deurlopend deur'n riometer vir elk van die 4 binnerigtings opgeneem met 'n

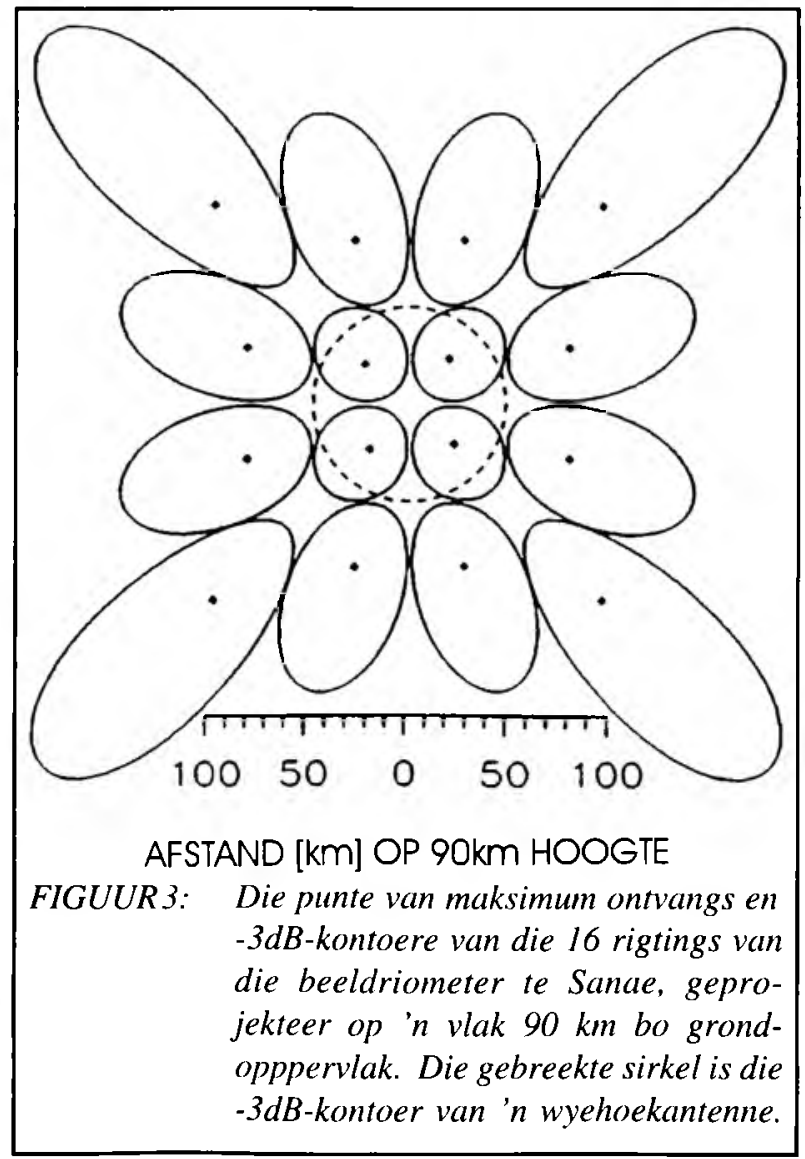

monsterfrekwensie van $4 \mathrm{~Hz}$, terwyl die 12 buiterigtings opeenvolgend op ' $n$ riometer in 'n periode van 3 sekonde geskakel is.

\section{RIOMETERABSORPSIES EN LIGGE- WENDHEID VAN AURORAS}

Omdat riometerabsorpsies deur elektrone van hoër energie as optiese opwekking tydens aurora veroorsaak word, moet uit kwantitatiewe metings op hierdie twee waarnemings die spektraalhardheid van presipiterende elektrone afgelei kan word. As die energiespektrum van elektrone in tyd onveranderd bly, sal die ionisasietempo per volume-eenheid, q, op 'n hoogte, h, eweredig wees aan die integrale optiese intensiteit I:

$q(h, t)=c_{1}(h) I(t)$

Die koëffisiënt $\mathrm{K}$ op 'n hoogte, h, vir absorpsie per hoogte-eenheid van kosmiese radiogolwe van 'n bepaalde frekwensie is eweredig aan die aantal vry elektrone per volume-eenheid, $\mathrm{N}$, op daardie hoogte:

$A(t)=\int K(h, t) d h=\int C_{2}(h) N(h, t) d h$

In (1) en (2) is $c_{1}$ en $c_{2}$ eweredigheidskonstantes. Die behoudsvergelyking vir vry elektrone in die D-laag kan geskryf word as

$\mathrm{dN} / \mathrm{dt}=\mathrm{q}-\propto \mathrm{N}^{2}$

waar $\propto$ dieeffektiewe rekombinasiekoëffisiënt op die hoogte $h$ is en waar aanvaar word dat die getaldigtheid van negatiewe ione verwaarloosbaar is teenoor dié van vry 
elektrone. Uit (3) volg dat onder ewewigsvoorwaardes $(\mathrm{dN} / \mathrm{dt}=0)$,

$N(h, t)=[\propto(h) q(h, t)]^{1 / 2}$

Uit (1), (2) en (4) volg:

$I^{1 / 2}(t)=\left[\left.\int c_{1}^{1 / 2} c_{2} \propto^{1 / 2} d h\right|^{-1} A(t)=c A(t)\right.$

Wanneer die energiespektrum verander, sal die konstante c'n funksie van die tyd wees. As'n maat van die hardheid van die spektrum van presipiterende elektrone kan ons dan skryf :

$\mathrm{R}=1 / \mathrm{c}(\mathrm{t})=\mathrm{A}(\mathrm{t}) / \mathrm{I}^{1 / 2}(\mathrm{t})$
Die parameter $\mathrm{R}$ sal toeneem soos die spektrum harder word.

\section{DIE MAGNETIESE SUBSTORM VAN 27 JULIE $1979^{7}$}

'n Magnetiese storm het op 26 Julie 1979 om 18:33 UT met 'n skielike impuls in die horisontale komponent van die aarde se magneetveld begin, soos magnetogramme wêreldwyd geregistreer het. Die effekte van hierdie storm is te Sanae met magnetometers, fotometers, ' $n$ kamera met $2 \pi$-ruimtehoek (geheellugkamera), 'n TV-kamera met lae liggevoeligheid, ' $n$ ionosond en riometers waargeneem deur deelnemers verbonde aan die Magnetiese Observatorium te Hermanus, Rhodes Universiteit te
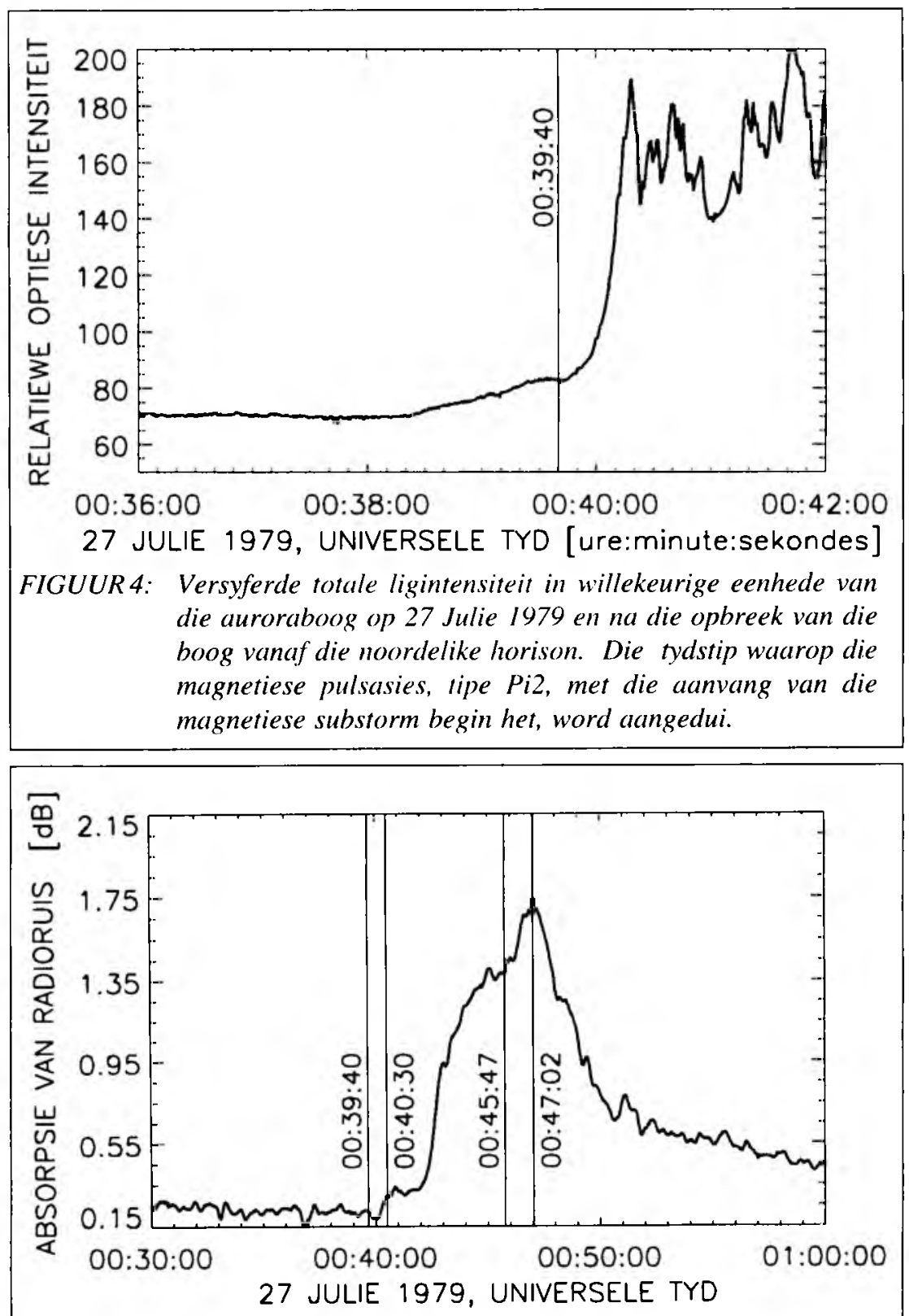

FIGUUR 5: Absorpsie van 30 Mhz kosmiese radioruis, soos gemeet met 'n wyehoekantenne, vir dieselfde gebeurtenis 27 Julie 1979 van figuur 4. Die auroraboog op die noordelike horison, het om 00:39:40 UT begin opbreek. Om 00:40:30UThet die absorpsie met 0,09 dB toegeneem en 'n maksimum om 00:47:02 UT bereik, na die maksimum van die optiese ligintensiteit om 00:45:47UT.
Grahamstad, Universiteit van Natal te Durban en die Potchefstroomse Universiteit. Hulle het 'n besondere studie van die magnetiese substorm, wat op 27 Julie 1979 om 00:40UT (wat feitlik gelyk is aan plaaslike tyd) begin het, gemaak. ${ }^{7}$ Hierdie ontleding en sintetisering van waarnemings verteenwoordig tot op hede die mees uitgebreide studie van 'n substorm met grondvlakinstrumentasie tesame met satellietdata van Geos 2 en 3 en van DMSR.

Die substorm het gedurende 'n periode van sterk magnetiese aktiwiteit $\left(\mathrm{K}_{\mathrm{p}} \approx 5-6\right)$ voorgekom. Met die aanvang van die substorm was daar'n auroraboog op die noordelike horison sigbaar. Hierdie boog het met die aanvang van die uitsettingsfase om ():40UT verhelder, opgebreek, vinnig poolwaarts beweeg en die hemelruim bo Sanae gevul. Die $\mathrm{H}_{\beta}$-uitstraling (afkomstig van protone, wat in die atmosfeer tot rus gekom het) het met 'n faktor minder as 2 toegeneem, terwyl die suurstof- en stikstofuitstralings (as gevolg van ionisasie deur elektrone in die hoë atmosfeer) met 3 tot 4 keer toegeneem het.

Die bevindinge was in ooreenstemming met die teorie dat magnetiese substorms voorafgegaan word deur 'n uitrek van die stert van die magnetosfeer en terselfdertyd 'n stadige ewenaarwaartse beweging van die rustige auroraboog terwyl die horisontale komponent van die aarde se magneetveld afneem. Tydens die aanvang van die substorm het die struktuur van die stertveld vinnig met gepaardgaande magnetiese pulsasies, tipe Pi2, verander, waardeur $6 \mathrm{keV}$ elektrone asook protone aan die voetpunte van die magneetveld 
gepresipiteer het. Elektrone en protone het saam beweeg gedurende die uitsetfase van die auroraboog, wat ongeveer 20 minute geduur het. Gedurende die herstelfase het die stert weer sy normale uitgerekte vorm genader, terwyl die auroraboog terug ewenaarwaarts na sy aanvangsposisie beweeg het. Elektron- en protonpresipitasie het daarna voortgeduur terwyl die energie van die presipiterende elektrone toegeneem het.

Die videokamera met lae liggevoeligheid van die Universiteit van Natal, Durban, was tydens die uitsetfase tot 00:42 UT op die auroraboog naby die noordelike horison gerig. Die boonste 20 beeldelemente van hierdie opname was die naaste aan die ontvangsveld van die riometerantenne, wat vertikaal gerig was. Figuur 4 vertoon die verloop van die versyferde totale ligintensiteit verkry van hierdie 20 beeldelemente. Die vertikale lyn is op
(0):39:40UT, die tydstip waarop die Pi2 magnetiese pulsasies begin het, geteken. In figuur 5 is die verloop van $30 \mathrm{MHz}$ absorpsie, soos verkry met 'n wyehoekantenne, geteken. Die geringe toename van $0,09 \mathrm{~dB}$ in absorpsie tot $00: 40: 30$ UT is waarskynlik toe te skryf aan die sterk toename van vry elektrone in die F-laag binne die ontvangskeël van die wyehoekantenne gedurende die aanvang van die optiese aurora.

Om 00:45:47 UT het die protonaurora 'n maksimum bereik, terwyl die optiese aurora om 00:46:00 UT verby sy maksimum was volgens die fotos van die geheellugkamera, wat elke minuut geneem is. Die opnames van die fotometers bevestig dat die proton-en elektronauroras gelyktydig hul maksima bereik het. Die later maksimum van die riometerabsorpsie om 00:47:02 UT dui op 'n verharding van die elektronspektrum gedurende die uitsettingsfase.

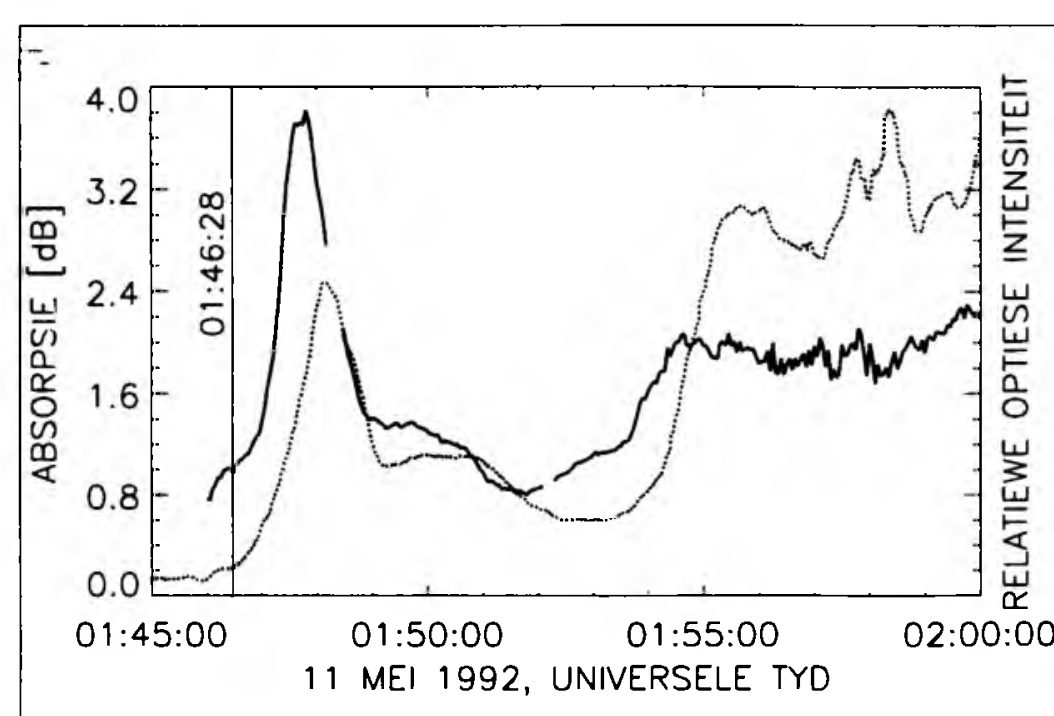

FIGUUR6: Die optiese intensiteit (vaste lyn) en absorpsie van $30 \mathrm{MHz}$ kosmiese radioruis vir 'n wyehoekantenne (stippellyn) op II Mei 1992. Om 01:46:20 UT is, net soos in figuur 5, 'n geringe toename in absorpsie waarneembaar nadat die opbreek van die auroraboog noord van Sanae om 01:45:20 begin het.

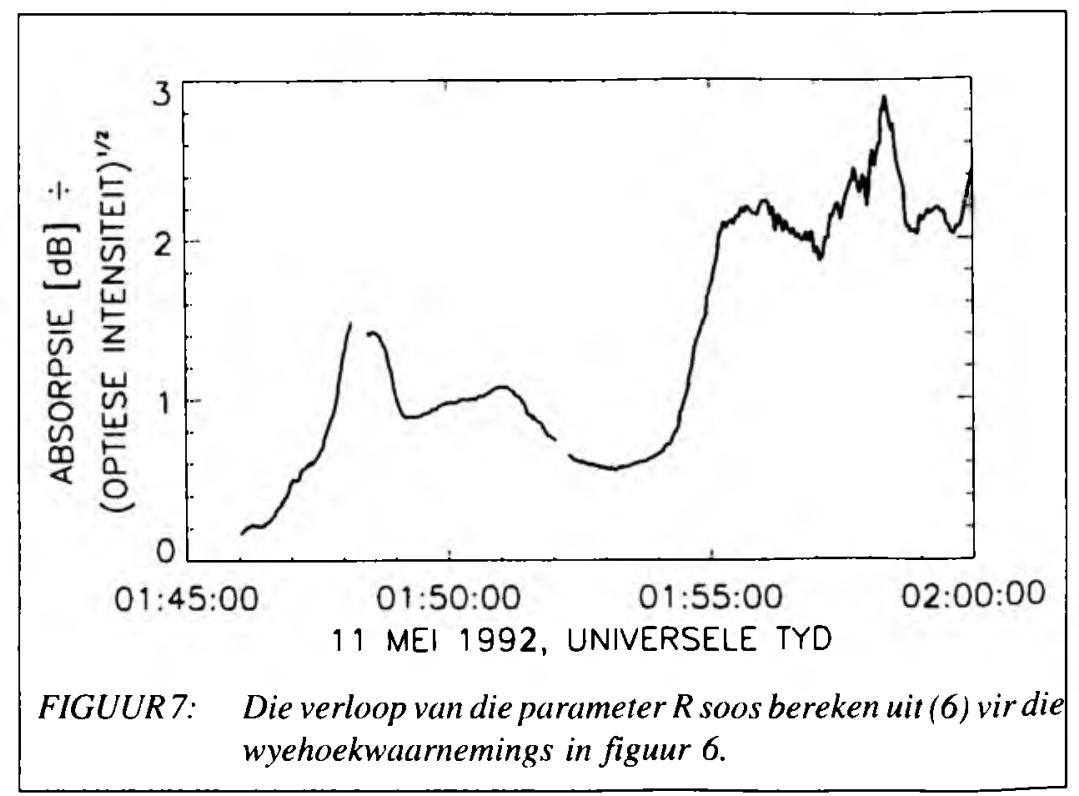

\section{DIE GEBEURTENIS VAN 11 MEI 1992}

Die stippellyn in figuur 6 vertoon die verloop van die $30 \mathrm{Mhz}$ riometerabsorpsie soos waargeneem met die wyehoekantenne vir gebeurtenisse op 11 Mei 1992, wat om $01: 45: 20$ UT met'n substorm begin het. Die intensiteit van die optiese aurora-uitstraling, soos opgeneem met ' $n$ videokamera van lae liggevoeligheid deur ' $n$ lens met $2 \pi$ ruimtehoek, is versyfer en integreer met invouing van die hoekafhanklike gevoeligheidsfunksie van die ontvangskeël van die wyehoekantenne van die riometer. Hierdie geïntegreerde optiese intensiteit is met 'n vaste lyn in figuur 6 geteken.

Die geringe toename van $0,09 \mathrm{~dB}$ in absorpsie vanaf $01: 45: 20$ tot $01: 46: 28$ UT kan weereens toegeskryf word aan aanvanklike ionisasie van die F-laag. Die ionisasie van die D-laag het daarna begin met 'n oploop in absorpsie tot die maksimum om 01:48:10 UT bereik is. Die vroeër maksimum in die optiese uitstraling, om 01:47:48 UT, dui op 'n verharding van die elektronspektrum gedurende die uitsetfase van die substorm, soos dit ook duidelik blyk uit die aanvanklike toename van die parameter $R=A / I^{1 / 2}$, wat in figuur 7 geteken is. Hierdie figuur toon verder dat $\mathrm{R}$ daarna weer afneem (elektronspektrum word sagter) gedurende die herstelfase, maar dat met hemuwe aktiwiteit vanaf $~ 01: 53$ UT (kyk ook figuur 6) die parameter weer sterk toeneem.

In figure 8 en 9 is die eerste substormpiek geteken onderskeidelik vir optiese uitstraling en vir riometerabsorpsie vir elk van die 4 binnekykrigtings van die beeldriometer waarvan die - $3 \mathrm{~dB}$-kontoere in figuur 3 geskets is. Figuur 8 toon aan dat daar nie noemenswaardige ruimtelike verskille in optiese uitstraling bestaan 

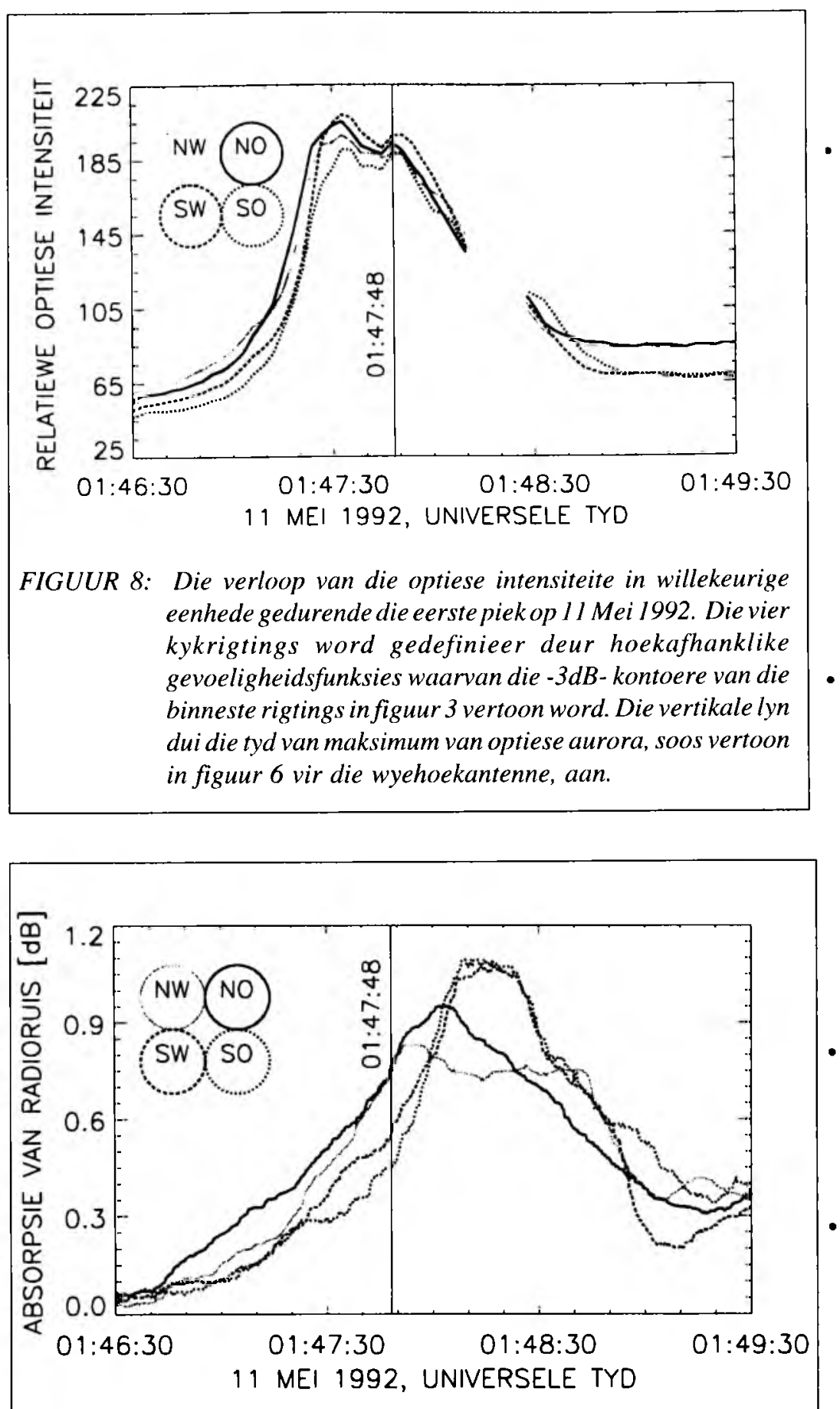

FIGUUR 9: Die absorpsies van 51,4 MHz kosmiese radioruis vir die eerste piek van 11 Mei 1992, gemeet in die binneste vier kykrigtings van die beeldriometer, soos gedefinieer deur die -3dB-kontoere in figuur 3. Die vertikale lyn dui die tyd van maksimum van optiese aurora, soos vertoon in figuur 6 vir die wyehoekantenne, aan.

daarop dat elektrone met energieë groter as $\sim 40 \mathrm{keV}$ nie eweredig verspreid vanuit die magnetosfeer bo die atmosfeer aankom nie, maar in ruimtelike strukture.

- Die waarnemings op die auroraprosesse, voortvloeiend uit die magnetiese substorm van 27 Julie 1979, was in ooreenstemming met die verwagtinge van die teorie van substorms. Die proton- en elektronauroras het feitlik gelyktydig maksimum uitstralings om 00:45:47 UT bereik. Die riometerabsorpsie het gelyktydig met die uitstralings van die proton- en elektronauroras begin, maar het 75 sekondes later om 00:47:02 UT 'n maksimum bereik. Dit dui op ' $n$ verharding van die spektrum van presipiterende elektrone vanaf die aanvang van die substorm.

- Net soos by die gebeurtenis van 27 Julie 1979 is aanvanklik ook 'n geringe toename van $0,09 \mathrm{~dB}$ in absorpsie na die aanvang van die substorm op $11 \mathrm{Mei}$ 1992 waargeneem. Hierdie aanvanklike toename word toegeskryf aan sagte elektrone, wat die F-laag van die ionosfeer geioniseer het toe die auroraboog vanaf die noordelike horison uitgesit het en die hemel oor Sanae oordek het.

- Die spektrum van auroraelektrone toon 'n aansienlike verharding vanaf die aanvang van die gebeurtenis op 11 Mei 1992, soos weergegee deur die parameter $R$ van (6).

- Waar optiese aurora nie noemenswaardige ruimtelike strukture tussen die vier binnekykrigtings van die 16-rigtingbeeldriometer vir die gebeurtenis van 11 Mei 1992 aantoon nie, is daarduidelike ruimtelike strukture in die absorpsiewaarnemings. Energieke auroraelektrone presipiteer daarom veel sterker gestruktureerd as die sagter elektrone wat optiese aurora in die F-laag veroorsaak.

\section{DANKBETUIGINGS}

tussen die vier kykrigtings na invouing van die gevoeligheidsfunksies oor die ontvangshoeke van elke kykrigting nie. Hierteenoor is daar volgens figuur 9 duidelike ruimtelike strukture waarneembaar in die presipitasie van energieke elektrone.

\section{GEVOLGTREKKINGS}

- Verhouding van absorpsies van kosmiese radioruis, soos waargeneem by verskillende frekwensies, dui
Die navorsing waarop hierdie bydrae berus, is moontlik gemaak deur die finansiële en logistiese ondersteuning deur die Departement van Omgewingsake. Die resultate is verkry deur toegewyde waarnemings van ekspedisielede gedurende oorwinterings te Sanae. In besonder kom dank en erkenning toe aan mnr. M.J. Mathews vir die versyfering van die optiese aurorabeelde, die verwerking van die $4 \mathrm{~Hz}$ riometerdata tot absorpsies in die verskillende kykrigtings en vir die lyntekeninge van die figure. 


\section{LITERATUURVERWYSINGS}

1. Hargreaves, J.K. (1979). The Upper Atmosphere and Solar Terrestrial Relations (Van Nostrand Reinhold, New York).

2. Stoker, P.H. \& Van Wyk, J.P. (1993), Riometer Observations at Sanae $(\mathrm{L}=4.0)$ related to Solar Proton Events, J. Geophys. Res. 98, 17, 429 - 17, 434.

3. Stoker, P.H. (1987). Riometer Absorption and Spectral Index for Precipitating Electrons with Exponential Spectra, J. Geophys. Res. 92, 5961 - 5968.

4. Drevin, G.R. \& Stoker, P.H. (1990). Riometer Quiet Day Curves determined by the Maximum Density Method, Radio Sci., 25, 1159-1166.
5. Detrick, D.L. (1988). A 16-beam phased-array radiowave imager for studies of cosmic noise absorption. Internal Report, Institute for Physical Science and Technology, University of Maryland, College Park, MD 20742.

6. Johansen, O.E. (1965). Variations in energy spectrum of auroral electrons detected by simultaneous observation with photometer and riometer, Planet. Space Sci, 13, 225 235.

7. Gledhill, J.A., Dore, I.S., Goertz, C.K., Haggard, R., Hughes, W.J., Scourfield, M.W.J., Smits, D.P., Stoker, P.H., Sutcliffe, P.R., Wakerley, P.A. \& Walker, A.D.M. (1987). A magnetospheric substorm observed at Sanae, Antarctica, J. Geophys. Res., 92, $2461-2475$. 